\title{
Comparison studies of the structural stability of rabbit prion protein with human and mouse prion proteins
}

\author{
Jiapu Zhang
}

Centre for Informatics and Applied Optimization,

Graduate School of Information Technology and Mathematics Sciences,

The University of Ballarat, MT Helen Campus, Victoria 3353, Australia,

Phone: 61-423487360,Email: jiapu_zhang@hotmail.com,j.zhang@ballarat.edu.au

\begin{abstract}
Background: Prion diseases are fatal and infectious neurodegenerative diseases affecting humans and animals. Rabbits are one of the few mammalian species reported to be resistant to infection from prion diseases isolated from other species (I. Vorberg et al., Journal of Virology 77 (3), 2003-2009 (2003)). Thus the study of rabbit prion protein structure to obtain insight into the immunity of rabbits to prion diseases is very important.
\end{abstract}

Findings: The paper is a straight forward molecular dynamics simulation study of wild-type rabbit prion protein (monomer cellular form) which apparently resists the formation of the scrapie form. The comparison analyses with human and mouse prion proteins done so far show that the rabbit prion protein has a stable structure. The main point is that the enhanced stability of the C-terminal ordered region especially helix 2 through the D177-R163 salt-bridge formation renders the rabbit prion protein stable. The salt bridge D201-R155 linking helix 3 and helix 1 also contributes to the structural stability of rabbit prion protein. The hydrogen bond H186-R155 partially contributes to the structural stability of rabbit prion protein.

Conclusions: Rabbit prion protein was found to own the structural stability, the salt bridges D177-R163, D201-R155 greatly contribute and the hydrogen bond H186-R155 partially contributes to this structural stability. The comparison of the structural stability of prion proteins from the three species rabbit, human and mouse showed that the human and mouse prion protein structures were not affected by the removing these two salt bridges. Dima et al. (Biophysical Journal 83, 1268-1280 (2002) and Proceedings of the National Academy of Sciences of the United States of America 101, 15335-15340 (2004)) also confirmed this point and pointed out that "correlated mutations that reduce the frustration in the second half of helix 2 in mammalian prion proteins could inhibit the formation of $\mathrm{PrP}^{\mathrm{Sc}}$ ".

Key words: Prion diseases; Immunity; Rabbit prion protein; Molecular dynamics. 
Submitted on $15 / 05 / 2010$, revised on $07 / 09 / 2010$, accepted on $15 / 10 / 2010$, available online 21/10/2010: http://dx.doi.org/10.1016/j.jtbi.2010.10.020

http://authors.elsevier.com/redirect/http://dx.doi.org/10.1016/j.jtbi.2010.10.020

\section{Introduction}

Prion diseases, including Creutzfeldt-Jakob disease (CJD), variant Creutzfeldt-Jakob diseases (vCJD), Gerstmann-Sträussler-Scheinker syndrome (GSS), Fatal Familial Insomnia (FFI), Kuru in humans, scrapie in sheep, bovine spongiform encephalopathy (BSE or 'mad-cow' disease) and chronic wasting disease (CWD) in cattle, etc., are invariably fatal and highly infectious neurodegenerative diseases affecting humans and animals. However, for treating all these diseases, there is no effective therapeutic approach ([Aguzzi et al., 2006, Prusiner, 1998, Weissmann, 2004]).

Many marvelous biological functions in proteins and DNA and their profound dynamic mechanisms ([chou, 1984a, 1984b, 1987, 1989, 1994, chou et al., 1988]) can be revealed by studying their internal motions ([Chou et al., 1988]). Likewise, to really understand the stability of rabbit prion molecules and their action mechanism, we should consider not only the static structures concerned but also the dynamical information obtained by simulating their internal motions or dynamic process ([Wang et al., 2009a, 2009b, 2009c, 2008a, 2008b, 2008c, 2009d, 2007a, 2007b, 2009e, 2009f, 2010]). Prion protein molecular dynamics (MD) simulation studies usually have been done on the C-terminal structured region, some C-terminal mutants, copper binding segments (e.g. HGGGW, GGGTH), and amyloid fibril segments (e.g. AGAAAAGA [Zhang, 2010b, Zhang et al., 2010c]). This paper is doing the MD simulation studies on the rabbit prion protein $\mathrm{C}$-terminal structured region.

Rabbits are one of the few mammalian species reported to be resistant to infection from prion diseases isolated from other species ([Vorberg et al., 2003]). Recently, the NMR molecular structures of wild-type, mutant S173N and mutant I214V rabbit prion proteins (124-228) were released into the Protein Data Bank ([Berman et al., 2000]) with PDB ID codes 2FJ3, 2JOH, 2JOM respectively. Zhang (2010a) studied these NMR structures by MD simulations and simulation results at $450 \mathrm{~K}$ under low and neutral $\mathrm{pH}$ environments confirmed the structural stability of wild-type rabbit prion protein. However, the previous MD simulation results at $500 \mathrm{~K}$ under neutral $\mathrm{pH}$ environment showed that wild-type rabbit prion protein (124-228) does not have more structural stability than human prion protein (125-228) (PDB ID code 1QLX) and mouse prion protein (124-226) (PDB ID code 1AG2) but the opposite holds ([Zhang, 2009]). In [Zhang, 2010a], the author did not carry on the MD simulations at $450 \mathrm{~K}$ under low and neutral pH environments for human prion protein (125-228) and mouse prion protein (124-226); this paper will do this work. Findings of this paper agree with the findings of [Zhang, 2010a], but disagree with the conclusion of [Zhang, 2009]. In order to further confirm the findings, this paper will do longer simulations than [Zhang, 2009, Zhang, 2010a]. 
The differences between [Zhang, 2009; Zhang, 2010a] are at: (1) Zhang (2009) did not do the simulations under low pH environments, but Zhang (2010a) did; (2) Zhang (2009) did the simulations at $500 \mathrm{~K}$, but Zhang (2010a) did the simulations at $450 \mathrm{~K}$; (3) Zhang (2009) did the simulations by Amber 8, but Zhang (2010a) by Amber 9; (4) Zhang (2009) did not study any mutant of rabbit prion protein, but Zhang (2010a) studied the mutants of rabbit prion protein; (5) Zhang (2009) studied human and mouse prion proteins, but Zhang (2010a) did not study human and mouse prion proteins; (6) In [Zhang, 2009] the time of equilibrations done in constant NPT ensembles under Berendsen thermostat was $20 \mathrm{~ns}$, but in [Zhang, 2010a] the equilibrations were done in constant NPT ensembles under Langevin thermostat for $5 \mathrm{~ns}$; the productions for [Zhang, 2009] were under Berendsen thermostat at $500 \mathrm{~K}$, but for [Zhang, 2010a] the productions were under Langevin thermostat at $450 \mathrm{~K}$.

The infectious prion protein (124-228) $\left(\mathrm{PrP}^{\mathrm{Sc}}\right)$ is an abnormally folded form of the normal cellular prion protein (124-228) $\left(\mathrm{PrP}^{\mathrm{C}}\right)$ and the conversion of $\operatorname{PrP}^{\mathrm{C}}$ to $\operatorname{PrP}^{\mathrm{Sc}}$ is believed to involve conformational change from a predominantly $\alpha$-helical protein (42\% $\alpha$-helix, $3 \% \beta$-sheet) to a protein rich in $\beta$-sheets (30\% $\alpha$-helix, $43 \% \beta$-sheet) ([Cappaia et al., 2004, Daude, 2004, Ogayar et al., 1998, Pan et al., 1993, Reilly, 2000]). This paper studies the NMR structures of wild-type human, mouse, and rabbit prion proteins by computer MD simulations, where the NMR structure of $\mathrm{PrP}^{\mathrm{C}}$ consists of $\beta$-strand 1, $\alpha$-helix 1, $\beta$-strand 2, $\alpha$-helix 2 and $\alpha$-helix 3. Simulation results of this paper show that the salt bridges D177-R163, D201-R155 greatly contribute to the structural stability of rabbit prion protein. We also find that the hydrogen bond H186-R155 partially contributes to the structural stability of rabbit prion protein.

\section{Materials and methods}

Simulation initial structure for the rabbit prion protein was built on $\operatorname{RaPrP}^{\mathrm{C}}(124$ 228) (PDB entry 2FJ3). Identical simulations were also done for human prion protein $\left(\mathrm{HuPrP}^{\mathrm{C}}(125-228)\right)$ and mouse prion protein $\left(\operatorname{MoPrP}^{\mathrm{C}}(124-226)\right)$. The initial simulation structures of human and mouse prion proteins were built on PDB entries 1QLX ([Berman et al., 2000, Zahn et al., 2000]) and 1AG2 ([Berman et al., 2000, Riek et al., 1996]), respectively. Simulation methods are completely same as the ones of [Zhang, 2010a]. $16 \mathrm{Cl}$-, $14 \mathrm{Cl}$-, $14 \mathrm{Cl}$-, and 5599 waters, 3836 waters, 5909 waters were separately added for the human, mouse, rabbit prion proteins under low $\mathrm{pH}$ environment. The step size of $2 \mathrm{fs}$ is typical for the SHAKE algorithm at $300 \mathrm{~K}$. At 450 $\mathrm{K}, 1 \mathrm{fs}$ was used as the step size. For prion proteins some MD works have been done at $500 \mathrm{~K}$ (e.g. [El-Bastawissy et al., 2001, Sekijima et al., 2003, Shamsir et al., 2005, Yang et al., 2005]); this paper does the MD simulations at $450 \mathrm{~K}$ and these simulations are not physically relevant.

Simulations were done under low $\mathrm{pH}$ and normal $\mathrm{pH}$ environments respectively. All the simulations were performed with the AMBER 9 package ([Case et al., 2006]), with analysis carried out using functionalities in AMBER 9 and AMBER 7 CARNAL ([Case et al., 2002]). Graphs were drawn by XMGRACE of Grace 5.1.21, DSSP 
([Kabsch et al., 1983]). The AMBER ff03 force field was used. The van der Waals and electrostatic interactions were treated by SHAKE algorithm and PMEMD algorithm with nonbonded cutoffs of 12 angstroms. The systems were surrounded with TIP3PBOX water molecules and neutralized by sodium ions, and optimized to remove bad hydrogen contacts. Then the systems were heated from $100 \mathrm{~K}$ to $450 \mathrm{~K}$ step by step during $3 \mathrm{~ns}$. The thermostat algorithm used is the Langevin thermostat algorithm in constant NVT ensembles. Equilibrations were done in constant NPT ensembles under Langevin thermostat for $5 \mathrm{~ns}$. After equilibrations, production MD phase was carried out at $450 \mathrm{~K}$ for $20 \mathrm{~ns}$ using constant pressure and temperature ensemble. All the simulations were performed on the Tango facilities of the Victoria Partnership for Advanced Computing of Australia (http://www.vpac.org).

\section{Results and discussion}

The MD simulations done at room temperature $300 \mathrm{~K}$ whether under neutral or low $\mathrm{pH}$ environment display very little fluctuation and no variation among rabbit, human and mouse prion proteins. At $450 \mathrm{~K}$ there are fluctuation and variation among rabbit, human and mouse prion proteins, but their backbone atom RMSDs (root mean square deviations) respectively calculated from their minimized structures and their radii of gyrations do not have great difference even under low $\mathrm{pH}$ environment (Fig.s 1-2). Their secondary structures under neutral $\mathrm{pH}$ environment at $450 \mathrm{~K}$, under low (Fig. 3) and neutral $\mathrm{pH}$ environments at $300 \mathrm{~K}$, do not change very much either. However, the secondary structures under low $\mathrm{pH}$ environment at $450 \mathrm{~K}$ have great differences between rabbit prion protein and human and mouse prion proteins (Fig.s 4-5): the $\alpha$-helices of rabbit prion protein were completely unfolded and began to turn into $\beta$-sheets but those of human and mouse prion proteins were not changed very much. These results indicate the C-terminal region of $\mathrm{RaPrP}^{\mathrm{C}}$ has lower thermostability than that of $\mathrm{HuPrP}^{\mathrm{C}}$ and $\mathrm{MoPrP}^{\mathrm{C}}$. Under the low $\mathrm{pH}$ environment, the salt bridges D177-R163, D201-R155 were removed (thus the free energies of the salt bridges changed the thermostability) so that the structure nearby the central helices 1-3 was changed for rabbit prion protein.

There always exist salt bridges (where the oxygen-nitrogen distance cut-off calculated for the salt bridges is 3.2 angstroms) between D202-R156, D178-R164 for human and mouse prion proteins, between D201-R155, D177-R163 for rabbit prion protein. The disulfide bond between C178-C213 links the 2nd and 3rd $\alpha$-helices and keeps several strong salt bridges linked. The salt bridge between D177-R163 keeps the linkage of the middle of $\alpha$-helix 2 and the coil at $\beta$-sheet 2 to $\alpha$-helix 2 . The salt bridge between D201-R155 makes the 3rd and 1st $\alpha$-helices linked. The salt link distances of D177-R163 and D201-R155 are illustrated in Fig.s 6-8. Except for the short period of break of the salt bridge N202-R156 of human prion protein during 8.5-10.5 ns, the salt bridges are always occupying human, mouse, and rabbit prion proteins. Under low $\mathrm{pH}$ environment, all these salt bridges were removed. They did not change the secondary structures of human and mouse prion proteins very much. However, rabbit prion protein is very sensitive to the low $\mathrm{pH}$ environment: the remove of these salt bridges led to the collapse of the stable helical structure of wild-type rabbit prion 
protein. Structural stability of a protein is determined by factors of hydrogen bond, van der Waals force, hydrophobic interaction, and salt bridge; change from neutral to low $\mathrm{pH}$ environments will break the salt bridges only. Thus, we might be able to say that salt bridges D177-R163, D201-R155 greatly contribute to the structural stability of rabbit prion protein. $\operatorname{RaPrP}^{\mathrm{C}}(124-228)$ apparently resists the formation of the scrapie form, and the enhanced stability of the C-terminal ordered region especially helix 2 through the D177-R163 salt-bridge formation renders the rabbit prion protein stable. The analyses of human and mouse prion proteins agree with the results of [Dima et al., 2002, Dima et al., 2004], where human and mouse prion proteins were showed lack of stability and correlated mutations that reduce the frustration in the second half of helix 2 in mammalian prion proteins could inhibit the formation of $\mathrm{PrP}^{\mathrm{Sc}}$.

The MD simulation experience of the NMR structure of human prion protein variant D178N (PDB ID: 2K1D, released on 03-MAR-2009) ([Mills et al., 2009]) of the author confirmed that the secondary structural performance of the D178N mutant under neutral $\mathrm{pH}$ environment at $450 \mathrm{~K}$ is same as that of the wild-type rabbit prion protein under low $\mathrm{pH}$ environment at $450 \mathrm{~K}$. Though the salt bridge R163-D177 in the structure of prion proteins spans only 14 residues and it should have a rather impact on the local structure, human and mouse prion proteins do not have the stable local structure kept by the salt bridge R164-D178. This agrees with experimental results of [Liemann et al., 1999], which showed a reduced stability if D178 was mutated into N178 for human prion protein. The MD simulation experience of the homology structure of rabbit prion protein of Zhang et al. (2006) also confirmed that rabbit prion protein has a more stable structure than human and mouse prion proteins, and the salt bridge and hydrogen bond between D177 and R163 plays a key important role to this stability.

Recently Zhong (2010) reported that for human prion protein (PDB entry 1QM0) the mutation of H187 into R187 makes the hydrogen bond H187-R156 broken, and the strong electrostatic repulsion between R187 and R156 drives both positively charged side chains away from their original positions leaving their hydrophobic core to be solvent accessible. For rabbit prion protein at $450 \mathrm{~K}$ under neutral $\mathrm{pH}$ environment, there is the hydrogen bond H186-R155 during more than $26.44 \%$ time of the 20 ns production trajectories; however, for mouse (PDB entry 1AG2) and human (PDB entry 1QLX) prion proteins at $450 \mathrm{~K}$ under the neutral $\mathrm{pH}$ environment, the hydrogen bond between H187 and R156 has been broken during the whole 20 ns production trajectories. The hydrogen bond H186-R155 clearly partially contributes to the structural stability of rabbit prion protein.

Besides $\mathrm{pH}$ deviations and the choice of temperatures, point mutations from wildtype can identify more contributing factors for the extraordinary stability of rabbit prion protein. Through the study of wild-type and its S173N variant, recently Wen et al. (2010a) suggested that the ordered loop 165-172 and its interaction with helix 3 , together with the unique distribution of surface electrostatic potential, significantly contribute to the unique structural characteristics of $\operatorname{RaPrP}^{\mathrm{C}}$; most recently, Wen et al. (2010b) studied the I214V mutant of rabbit prion protein and suggested that this mutation results in a prominent global shift of surface charge distribution and an in- 
crease of backbone flexibility on a ps-ns time scale. Sweeting et al. (2009) pointed out the rabbit prion mutants of S170N, S174N, and S170N/S174N break the hydrogen bond network of residues 170-174.

The choice of temperatures is important and the choosing $450 \mathrm{~K}$ for this paper is very significant. At $300 \mathrm{~K}$, the MD results display little difference among rabbit, human and mouse prion protein structures whether under neutral or low $\mathrm{pH}$ environments. At $500 \mathrm{~K}$, Zhang (2009) found that under neutral $\mathrm{pH}$ environment the structure of rabbit is not more stable than these of human and mouse but the opposite holds. However, at $450 \mathrm{~K}$, this present paper found that the structure of rabbit is much more stable than these of human and mouse; this agrees with the experimental results of rabbit prion protein and shows that the choosing $450 \mathrm{~K}$ of this paper is significant.

Recent experimental results on mouse and rabbit prion proteins showed that rabbit specific residues surrounding the GPI anchor attachment site inhibit prion infection ([Nisbet et al., 2010]). We find rabbit prion protein has a C-terminal residue R227 forming a hydrogen bond/salt bridge network with other inner residues but mouse prion protein has no such an arginine residue at the end of C-terminal.

\section{Conclusion}

The paper is a straight forward MD simulation study of rabbit prion protein (monomer cellular form) which apparently resists the formation of the scrapie form. The analyses of MD simulation results confirmed the structural stability of rabbit prion protein under neutral $\mathrm{pH}$ environment. The main point is that the enhanced stability of the C-terminal ordered region especially helix 2 through the D177-R163 salt-bridge formation renders the rabbit prion protein stable. The salt bridge D201-R155 linking helix 3 and helix 1 also contributes to the structural stability of rabbit prion protein. The comparison of the structural stability of prion proteins from the three species rabbit, human and mouse showed that the human and mouse prion protein structures were not affected by the removing these two salt bridges. We also find that the hydrogen bond H186-R155 partially contributes to the structural stability of rabbit prion protein.

Acknowledgments: The author appreciates the anonymous referees for the numerous insightful comments, which have improved this paper greatly. This paper was finished in 2010 without any research fund thus I am in debt to the supports from my family. Thanks go to mother's love; this paper is dedicated to celebrate the 70th birthday of my mother Ms. Xian'ai Liu.

\section{References}

[Aguzzi et al., 2006] Aguzzi A., Heikenwalder M., 2006. Pathogenesis of prion diseases: current status and future outlook. Nat. Rev. Microbiol. 4, 765-775. 
[Berman et al., 2000] Berman H.M., Westbrook J., Feng Z., Gilliland G., Bhat T.N., Weissig H., Shindyalov I.N., Bourne P.E., 2000. The protein data bank. Nucleic Acids Res. 28, 253-242.

[Cappaia et al., 2004] Cappaia R., Collinsa S.J., 2004. Structural biology of prions. Rabenau H.F., Cinatl J., Doerr H.W. (eds): Prions. A Challenge for Science, Medicine and the Public Health System. Contrib Microb. Basel, Karger 11, 1432 .

[Case et al., 2002] Case D.A., Pearlman J.W., Caldwell T.E., Cheatham III, Wang J., Ross W.S., Simmerling C.L., Darden T.A., Merz K.M., Stanton R.V., Cheng A.L., Vincent J.J., Crowley M., Tsui V., Gohlke H., Radmer R.J., Duan Y., Pitera J., Massova I., Seibel G.L., Singh U.C., Weiner P.K., Kollman P.A., 2002. AMBER 7, University of California: San Francisco.

[Case et al., 2006] Case D.A., Darden T.A., Caldwell T.E., Cheatham III, Simmerling C.L., Wang J., Duke R.E., Luo R., Merz K.M., Pearlman D.A., Crowley M., Walker R.C., Zhang W., Wang B., Hayik S., Roitberg A., Seabra G., Wong K.F., Paesani F., Wu X., Brozell S., Tsui V., Gohlke H., Yang L., Tan C., Mongan J., Hornak V., Cui G., Beroza P., Mathews D.H., Schafmeister C., Ross W.S., Kollman P.A., 2006. AMBER 9, University of California: San Francisco.

[Chou, 1984a] Chou K.C., 1984a. The biological functions of low-frequency phonons: 3. Helical structures and microenvironment. Biophys. J. 45, 881-890.

[Chou, 1984b] Chou K.C., 1984b. The biological functions of low-frequency phonons: 4. Resonance effects and allosteric transition. Biophys. Chem. 20, 61-71.

[Chou, 1987] Chou K.C., 1987. The biological functions of low-frequency phonons: 6 . A possible dynamic mechanism of allosteric transition in antibody molecules. Biopolymers 26, 285-295.

[Chou, 1988] Chou K.C., 1988. Review: low-frequency collective motion in biomacromolecules and its biological functions. Biophys. Chem. 30, 3-48.

[Chou, 1989] Chou K.C., 1989. Low-frequency resonance and cooperativity of hemoglobin. Trends Biochem. Sci. 14, 212.

[Chou et al., 1988] Chou K.C., Mao B., 1988. Collective motion in DNA and its role in drug intercalation. Biopolymers 27, 1795-1815.

[Chou et al., 1994] Chou, K.C., Zhang, C.T., Maggiora, G.M., 1994. Solitary wave dynamics as a mechanism for explaining the internal motion during microtubule growth. Biopolymers 34, 143-153

[Daude, 2004] Daude N., 2004. Prion diseases and the spleen.Viral Immunology 17, $334-349$.

[Dima et al., 2002] Dima R.I., Thirumalai D., 2002. Exploring the propensities of helices in $\mathrm{PrP}^{\mathrm{C}}$ to form $\beta$ sheet using NMR structures and sequence alignments. Biophys. J. 83, 1268-1280. 
[Dima et al., 2004] Dima R.I., Thirumalai D., 2004. Probing the instabilities in the dynamics of helical fragments from mouse $\mathrm{PrP}^{\mathrm{C}}$. Proc. Natl. Acad. Sci. USA 101, 15335-15340.

[El-Bastawissy et al., 2001] El-Bastawissy E., Knaggs M.H., Gilbert I.H., 2001. Molecular dynamics simulations of wild-type and point mutation human prion protein at normal and elevated temperature. J. Mol. Graph. Model. 20, 145-154.

[Kabsch et al., 1983] Kabsch W., Sander C., 1983. Dictionary of protein secondary structure: pattern recognition of hydrogen-bonded and geometrical features. Biopolymers 22, 2577-2637.

[Liemann et al., 1999] Liemann S., Glockshuber R., 1999. Influence of amino acid substitutions related to inherited human prion diseases on the thermodynamic stability of the cellular prion protein. Biochem. 38, 3258-67.

[Mills et al., 2009] Mills N.L., Surewicz K., Surewicz W.K., Sonnichsen F.D., 2009, to be published. Residue 129 polymorphism and conformational dynamics of familial prion diseases associated with the human prion protein variant D178N. DOI: $10.2210 / \mathrm{pdb} 2 \mathrm{k} 1 \mathrm{~d} / \mathrm{pdb}$ http://www.rcsb.org/pdb/explore/explore.do?structureId=2K1D

[Nisbet et al., 2010] Nisbet R.M., Harrison C.F., Lawson V.A., Masters C.L., Cappai R., Hill A.F., 2010. Residues surrounding the GPI anchor attachment site of PrP modulate prion infection: insight from the resistance of rabbits to prion disease. J. Virol. 84 (13), 6678-86.

[Ogayar et al., 1998] Ogayar A., Snchez-Prez M., 1998. Prions: an evolutionary perspective. Internatl. Microbiol. 1, 183-190.

[Pan et al., 1993] Pan K.M., Baldwin M., Nguyen J., 1993. Conversion of $\alpha$-helices into $\beta$-sheets features in the formation of the scrapie prion proteins. Proc. Natl. Acad. Sci. USA 90, 10962-6.

[Prusiner, 1998] Prusiner S.B., 1998. Prions. Proc. Natl. Acad. Sci. USA 95, 1336313383.

[Reilly, 2000] Reilly C.E., 2000. Nonpathogenic prion protein $\left(\mathrm{PrP}^{\mathrm{C}}\right)$ acts as a cellsurface signal transducer. J. Neurol. 247, 819-820.

[Riek et al., 1996] Riek R., Hornemann S., Wider G., Billeter M., Glockshuber R., Wuthrich K., 1996. NMR structure of the mouse prion protein domain $\operatorname{PrP}(121-$ 231). Nature 382, 180-182.

[Sekijima et al., 2003] Sekijima M., Motono C., Yamasaki S., Kaneko K., Akiyama Y., 2003. Molecular dynamics simulation of dimeric and monomeric forms of human prion protein: insight into dynamics and properties. Biophys. J. 85, 1176-1185.

[Shamsir et al., 2005] Shamsir M.S., Dalby A.R., 2005. One gene, two diseases and three conformations: molecular dynamics simulations of mutants of human prion 
protein at room temperature and elevated temperatures. PROTEINS: Struct., Funct., and Bioinf. 59, 275-290.

[Sweeting et al., 2009] Sweeting B., Brown E., Chakrabartty A.,Pai E.F., 2009. The structure of rabbit $\mathrm{PrP}^{\mathrm{C}}$ : clues into species barrier and prion disease susceptibility. Canadian Light Source 28:

http://www.lightsource.ca/science/pdf/activity_report_2009/28.pdf

[Vorberg et al., 2003] Vorberg I., Martin H.G., Eberhard P., Suzette A.P., 2003. Multiple amino acid residues within the rabbit prion protein inhibit formation of its abnormal isoform. J. Virol. 77, 2003-2009.

[Wang et al., 2009a] Wang J.F., Chou K.C., 2009. Insight into the molecular switch mechanism of human Rab5a from molecular dynamics simulations. Biochem. Biophys. Res. Commun. 390, 608-12.

[Wang et al., 2009b] Wang J.F., Gong K., Wei D.Q., Li Y.X., Chou K.C., 2009. Molecular dynamics studies on the interactions of PTP1B with inhibitors: from the first phosphate-binding site to the second one. Protein Eng. Des. Sel. 22, 349-55.

[Wang et al., 2009c] Wang J.F., Wei D.Q., 2009. Role of structural bioinformatics and traditional Chinese medicine databases in pharmacogenomics. Pharmacogenomics $10,1213-5$.

[Wang et al., 2008a] Wang J.F., Wei D.Q., Chen C., Li Y., Chou K.C., 2008. Molecular modeling of two CYP2C19 SNPs and its implications for personalized drug design. Protein Pept. Lett. 15, 27-32.

[Wang et al., 2008b] Wang J.F., Wei D.Q., Chou K.C., 2008. Pharmacogenomics and personalized use of drugs. Curr. Top. Med. Chem. 8, 1573-9.

[Wang et al., 2008c] Wang J.F., Wei D.Q., Chou K.C., 2008. Drug candidates from traditional Chinese medicines. Curr. Top. Med. Chem. 8, 1656-65.

[Wang et al., 2009d] Wang J.F., Wei D.Q., Chou K.C., 2009. Insights from investigating the interactions of adamantane-based drugs with the M2 proton channel from the H1N1 swine virus. Biochem. Biophys. Res. Commun. 388, 413-7.

[Wang et al., 2007a] Wang J.F., Wei D.Q., Li L., Zheng S.Y., Li Y.X., Chou K.C., 2007. 3D structure modeling of cytochrome P450 2C19 and its implication for personalized drug design. Biochem. Biophys. Res. Commun. 355, 513-9.

[Wang et al., 2007b] Wang J.F., Wei D.Q., Lin Y., Wang Y.H., Du H.L., Li Y.X., Chou K.C., 2007. Insights from modeling the 3D structure of NAD $(\mathrm{P}) \mathrm{H}$-dependent Dxylose reductase of Pichia stipitis and its binding interactions with NAD and NADP. Biochem. Biophys. Res. Commun. 359, 323-9.

[Wang et al., 2009e] Wang J.F., Yan J.Y., Wei D.Q., Chou K.C., 2009. Binding of CYP2C9 with diverse drugs and its implications for metabolic mechanism. Med. Chem. 5, 263-70. 
[Wang et al., 2009f] Wang J.F., Zhang C.C., Chou K.C., Wei D.Q., 2009. Structure of cytochrome p450s and personalized drug. Curr. Med. Chem. 16, 232-44.

[Wang et al., 2010] Wang Y., Wei D.Q., Wang J.F., 2010. Molecular dynamics studies on T1 lipase: insight into a double-flap mechanism. J. Chem. Inf. Model. 50, $875-878$.

[Weissmann, 2004] Weissmann C., 2004. The state of the prion. Nat. Rev. Microbiol. $2,861-871$.

[Wen et al., 2010a] Wen Y., Li J., Yao W.M., Xiong M.Q., Hong J., Peng Y., Xiao G.F., Lin D.H., 2010. Unique structural characteristics of the rabbit prion protein. J. Bio. Chem. 285 (41), 31682-93.

[Wen et al., 2010b] Wen Y., Li J., Xiong M.Q., Peng Y., Yao W.M., Hong J., Lin D.H., 2010. Solution structure and dynamics of the $\mathrm{I} 214 \mathrm{~V}$ mutant of the rabbit prion protein. PLoS One 5(10): e13273.

[Yang et al., 2005] Yang S.C., Levine H., Onuchic J.N., Cox D.L., 2005. Structure of infectious prions: stabilization by domain swapping. FASEB J. 19, 1778-1782.

[Zahn et al., 2000] Zahn R., Liu A.Z., Luhrs T., Riek R., Schroetter C.V., Garcia F.L., Billeter M., Calzolai L., Wider G., Wuthrich K., 2000. NMR solution structure of the human prion protein. Proc. Natl. Acad. Sci. USA 97, 145-150.

[Zhang, 2009] Zhang J.P., 2009. Studies on the structural stability of rabbit prion probed by molecular dynamics simulations. J. Biomol. Struct. Dyn. 27, 159-162.

[Zhang, 2010a] Zhang J.P., 2010. Studies on the structural stability of rabbit prion probed by molecular dynamics simulations of its wild-type and mutants. J. Theor. Bio. 264, 119-122.

[Zhang, 2010b] Zhang J.P., 2010. Optimal molecular structures of prion AGAAAAGA amyloid fibrils formatted by simulated annealing. J. Mol. Model. DOI: 10.1007/s00894-010-0691-y. http://www.springerlink.com/content/15kk5k208u4853g8/

[Zhang et al., 2010c] Zhang J.P., Sun J., 2010. Optimal atomic-resolution structures of prion AGAAAAGA amyloid fibrils probed by hybrid local and global optimization searches. Proceedings of the International Conference on Optimization and Control 2010, 91-112: http://sci.gzu.edu.cn/icoco/ICOCO-Proceedings.pdf

[Zhang et al., 2006] Zhang J.P., Varghese J.N., Epa, V.C., 2006. Studies on the conformational stability of the rabbit prion protein. CSIRO Preventative Health National Research Flagship Science Retreat, Aitken Hill, Melbourne, 12-15 September 2006, Poster in Excellence: http://sites.google.com/site/jiapuzhang/

[Zhong, 2010] Zhong L.H., 2010. Exposure of hydrophobic core in human prion protein pathogenic mutant H187R. J. Biomol. Struct. Dyn. 28 (3), 355-61. 

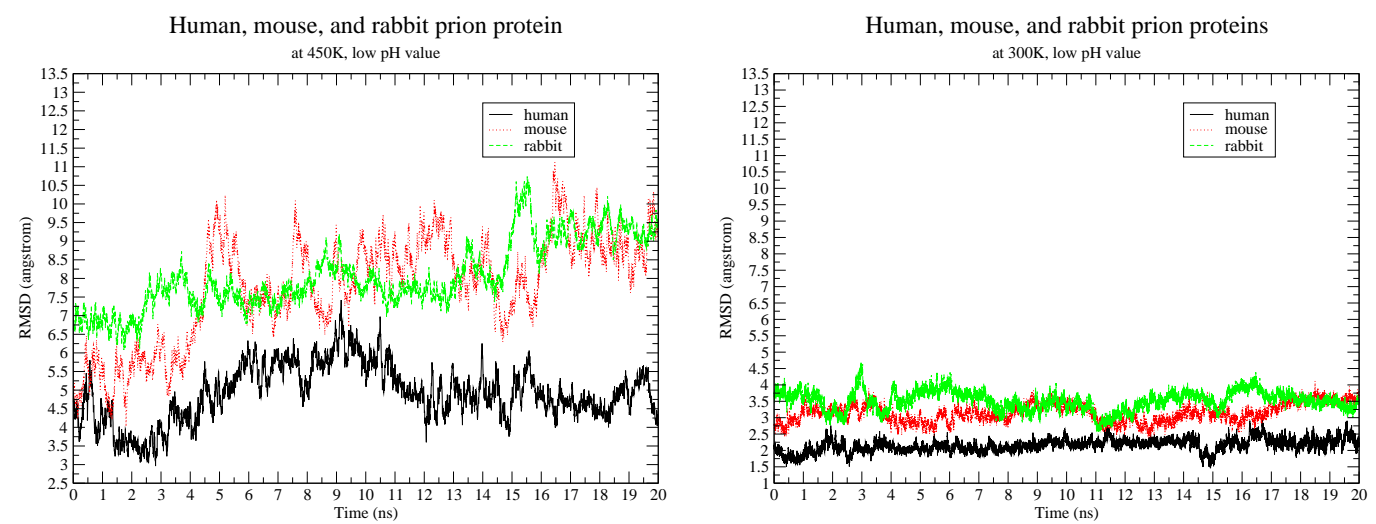

Figure 1: Backbone atom RMSD graphs for human, mouse, rabbit prion proteins.
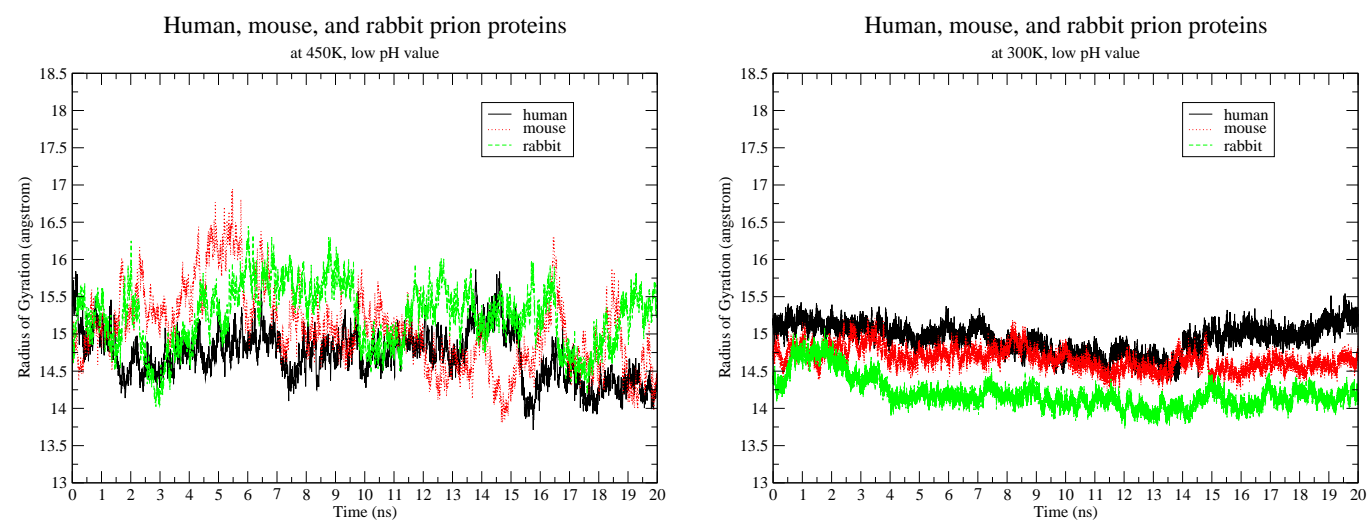

Figure 2: Radius Of Gyration graphs for human, mouse, rabbit prion proteins. 


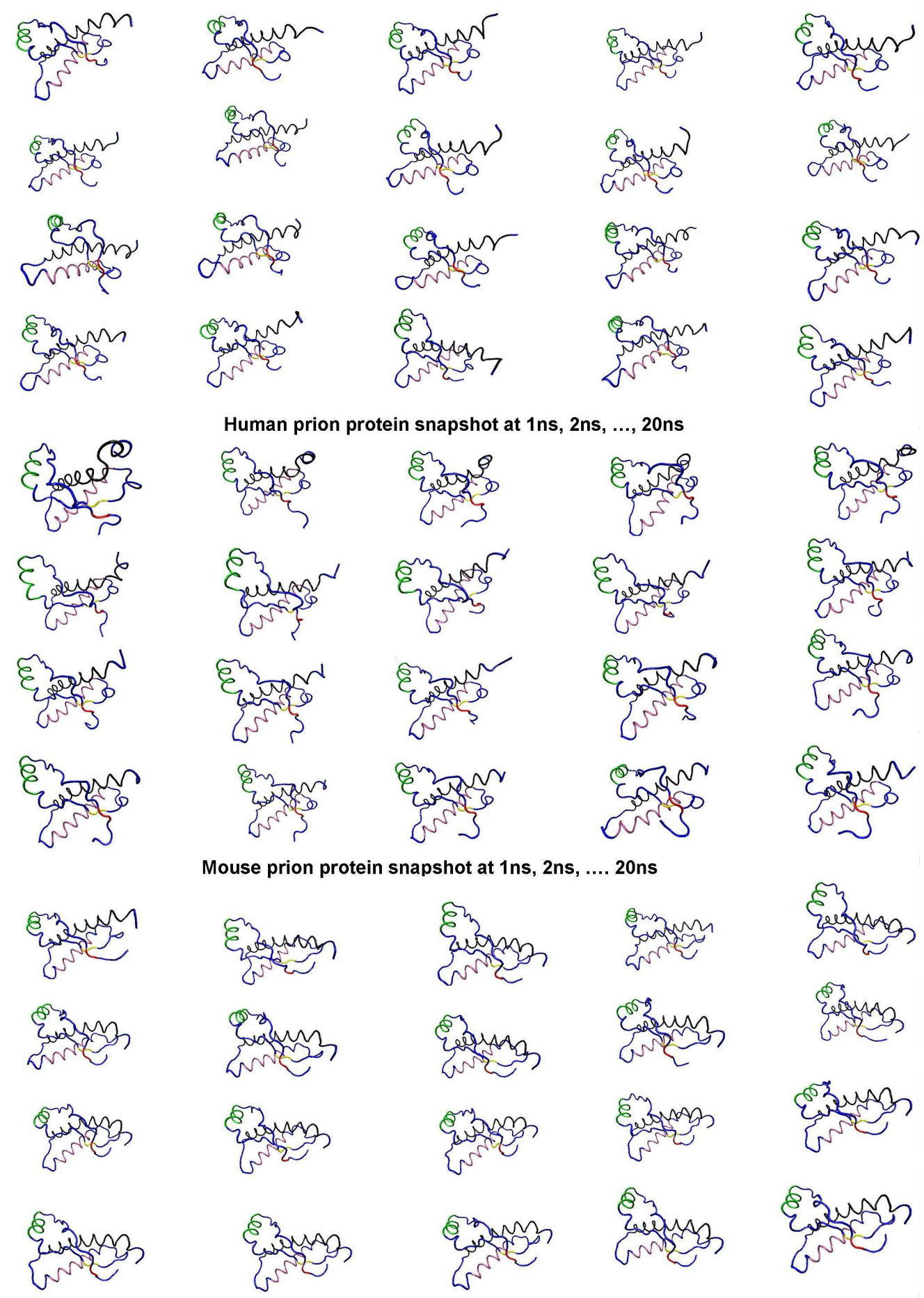

Rabbit prion protein snapshot at 1ns, 2ns, ..., 20ns

Figure 3: Snapshots of human, mouse, and rabbit prion proteins at $300 \mathrm{~K}$ under low $\mathrm{pH}$ environment. 


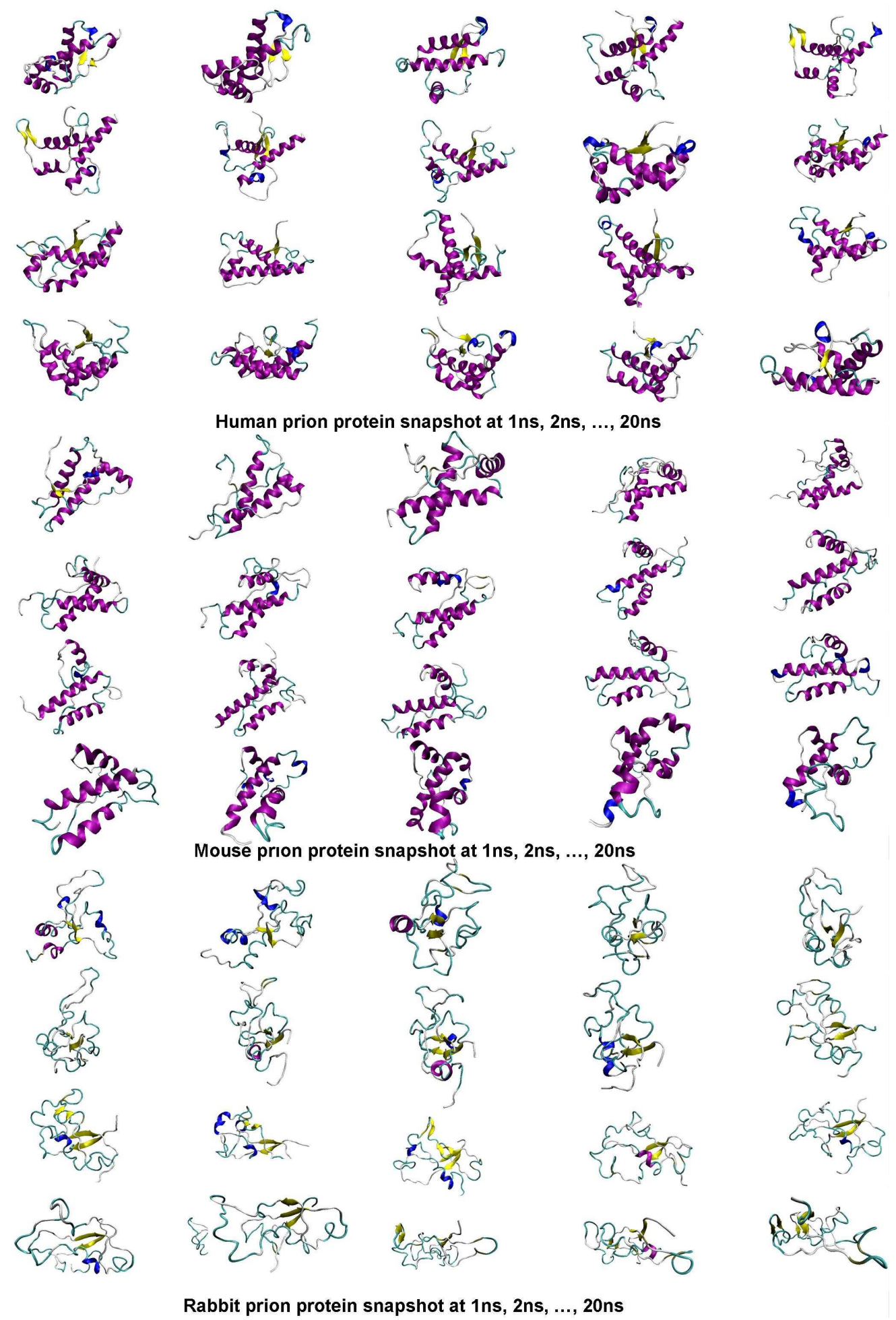

Figure 4: Snapshots of human, mouse, and rabbit prion proteins at $450 \mathrm{~K}$ under low $\mathrm{pH}$ environment. 

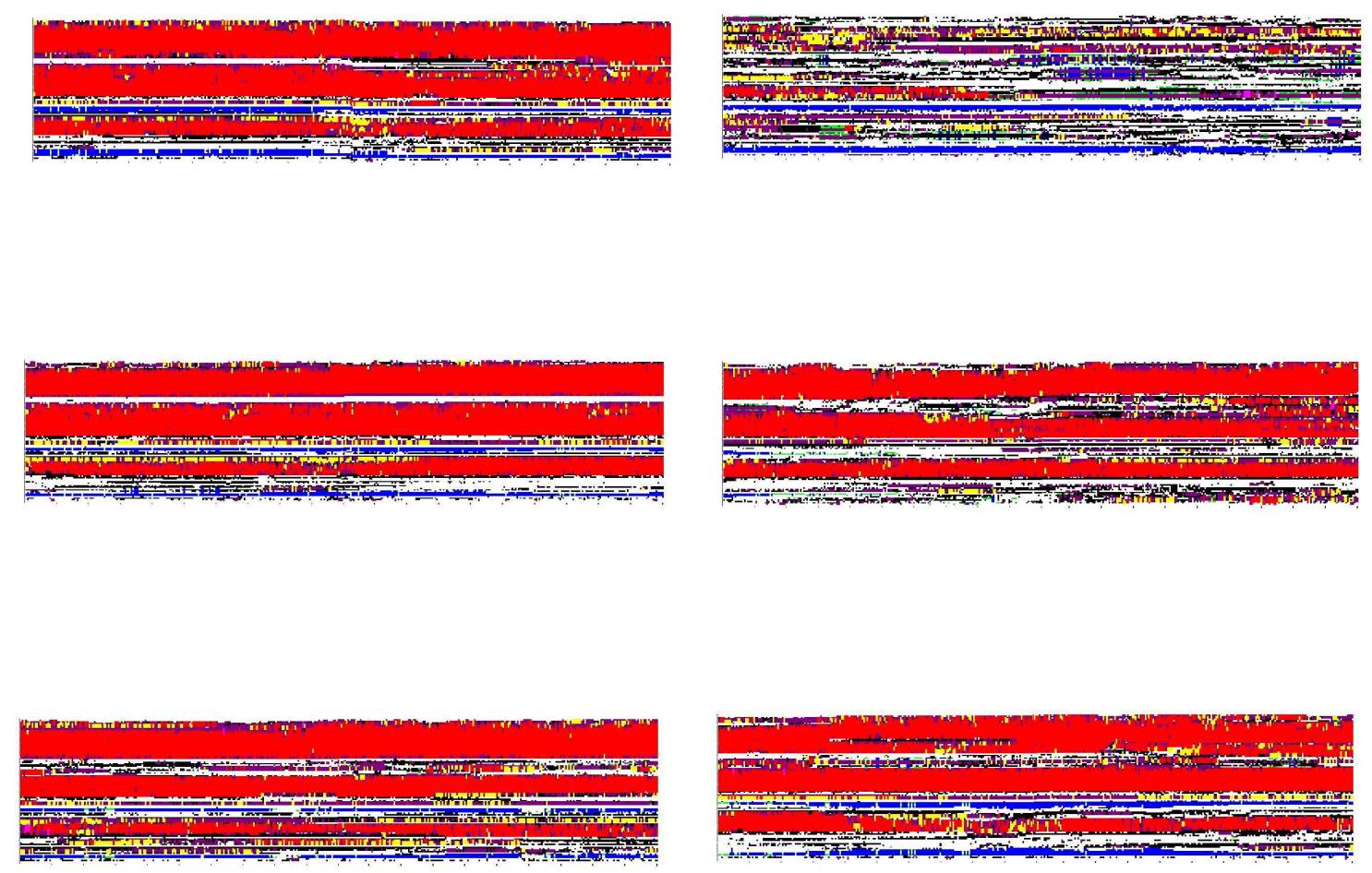

Figure 5: Secondary structures of rabbit, human and mouse prion proteins (from up to down) at $450 \mathrm{~K}$ under neutral and low (from left to right) $\mathrm{pH}$ environments. (red: $\alpha$ Helix, pink: $\pi$ - Helix, yellow: $3_{10}$-Helix, green: $\beta$-Bridge, blue: $\beta$-Sheet, purple: Turn, Black: Bend; x-axis: time (0 ns-20 ns), y-axis: residue numbers.)
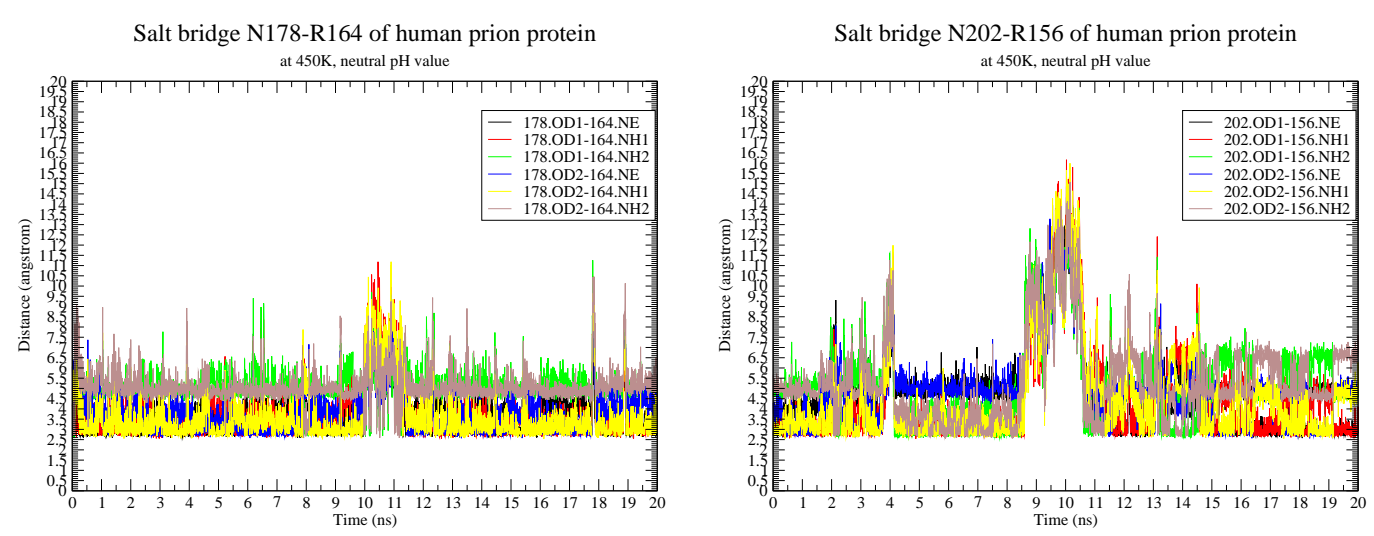

Figure 6: Salt Bridges of human prion protein at $450 \mathrm{~K}$ under neutral $\mathrm{pH}$ environment. 

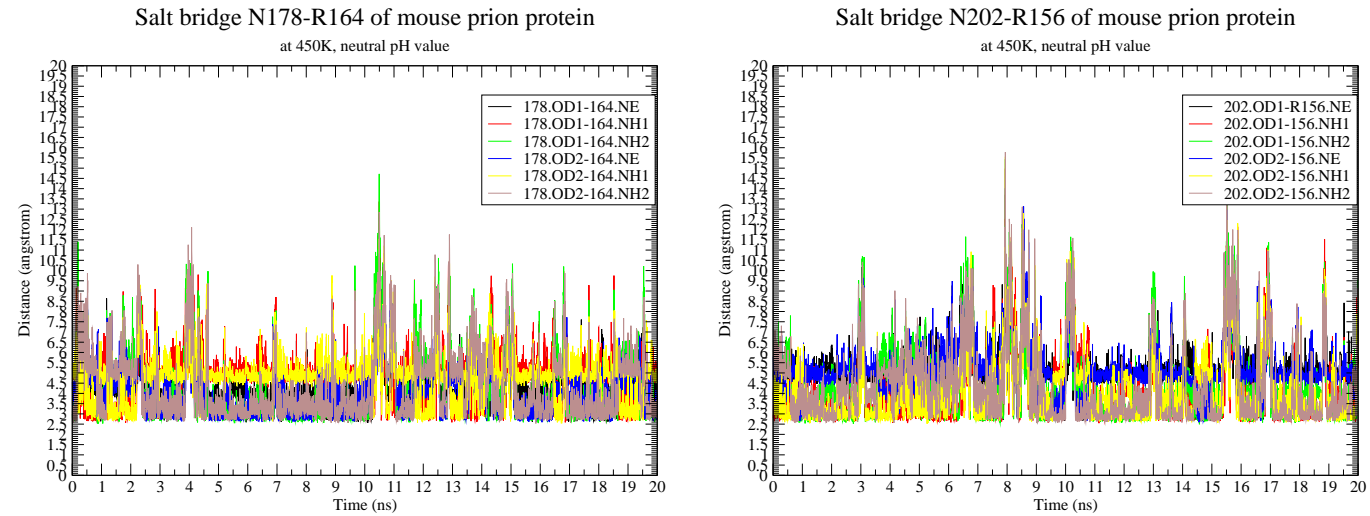

Figure 7: Salt Bridges of mouse prion protein at $450 \mathrm{~K}$ under neutral pH environment.
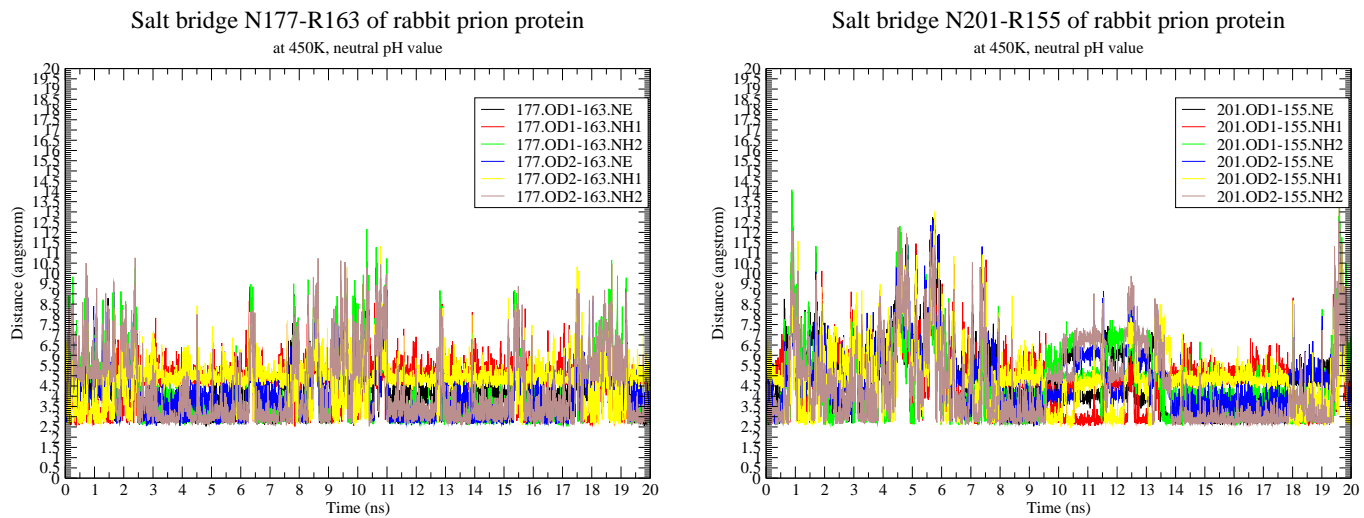

Figure 8: Salt Bridges of rabbit prion protein at $450 \mathrm{~K}$ under neutral $\mathrm{pH}$ environment. 